\title{
Psychological morbidity as a moderator of intention to quit smoking: a study of smokers and former smokers*
}

\author{
Morbidade psicológica como moderador da intenção para deixar de fumar: \\ um estudo com fumantes e ex-fumantes
}

\author{
Maria Fernanda Besteiro Afonso, Maria Graça Pereira Alves
}

\begin{abstract}
Objective: To analyze psychological morbidity as a moderator of the relationship between smoking representations and quality of life in smokers and former smokers, as well as to determine which psychological variables discriminate between smokers with and without the intention to quit smoking. Methods: This was a quantitative, correlational cross-sectional study involving a convenience sample of 224 smokers and 169 former smokers. Results: In smokers and former smokers, psychological morbidity had a moderating effect on the relationship between mental/physical quality of life and smoking representations (cognitive representations, emotional representations, and comprehensibility). Smokers with the intention to quit smoking more often presented with low comprehensibility, threatening emotional representations, behavioral beliefs, and perceived behavioral control, as well as with normative/control beliefs, than did those without the intention to quit. Conclusions: The results of this study underscore the importance of the moderating effect exerted by psychological morbidity, as well as that of sociocognitive variables, among smokers who have the intention to quit smoking.
\end{abstract}

Keywords: Smoking/psychology; Smoking cessation; Smoking/prevention \&t control.

\section{Resumo}

Objetivo: Analisar a morbidade psicológica como um moderador na relação entre as representações do tabaco e a qualidade de vida em fumantes e ex-fumantes, assim como conhecer as variáveis psicológicas que discriminam os fumantes com e sem intenção para deixar de fumar. Métodos: Estudo quantitativo, correlacional e transversal com uma amostra de conveniência constituída por 224 fumantes e 169 ex-fumantes. Resultados: Verificou-se um efeito moderador da morbidade psicológica na relação entre a qualidade de vida (física e mental) e as representações do tabaco (representações cognitivas e emocionais e compreensão) nos fumantes e nos ex-fumantes. Os fumantes com intenção para deixar de fumar apresentavam menor compreensão, representações emocionais mais ameaçadoras, mais crenças de comportamento, maior controle comportamental percebido e mais crenças normativas/controle do que aqueles sem essa intenção. Conclusões: Os resultados deste estudo enfatizam a importância da morbidade psicológica como moderadora, bem como das variáveis sociocognitivas, junto dos fumantes que querem deixar de fumar.

Descritores: Hábito de fumar/psicologia; Abandono do hábito de fumar; Hábito de fumar/prevenção ct controle.

*Study carried out at the University of Minho School of Psychology, Braga, Portugal.

Correspondence to: Fernanda Afonso. Rua dos Passionistas, 110, $4^{\circ}$ Esquerdo, 4520-292, Santa Maria da Feira, Portugal.

Tel. 351917400290. E-mail: fernandafonso@gmail.com

Financial support: None.

Submitted: 29 January 2013. Accepted, after review: 16 May 2013. 


\section{Introduction}

The literature on smoking has underscored that tobacco consumption is potentially fatal and that nicotine in particular is highly addictive. ${ }^{(1)}$ Successful smoking cessation requires a structured intervention, this type of intervention being more effective in helping smokers to quit. ${ }^{(2)}$

The literature shows a relationship between psychological morbidity (depression, anxiety, and stress) and the use of substances, including nicotine. ${ }^{(3)}$ It is a relationship between smoking and the presence of symptoms related to depression, ${ }^{(3)}$ anxiety, ${ }^{(4)}$ and stress. ${ }^{(5)}$

In terms of quality of life, the literature shows that smoking is a risk behavior that has a major impact on health. ${ }^{(6)}$ In contrast, not smoking is associated with better physical and mental quality of life. ${ }^{(7)}$

Many smokers do not regard smoking as a health problem and minimize their nicotine dependence; that is, they harbor misconceptions about smoking. ${ }^{(8)}$ According to the literature, the way individuals perceive their health and disease has important implications for their behavior, ${ }^{(9)}$ as is the case with smoking. Smoking representations are categorized into cognitive representations (which evaluate the perceived health effects of smoking, the duration of smoking, control, the effectiveness of smoking cessation treatment, and how smokers identify smoking-related symptoms); emotional representations (which evaluate smokingrelated concerns and how smokers feel emotionally affected); and comprehensibility (i.e., individuals' level of understanding of their smoking behavior). Threatening cognitive representations, emotional representations, and comprehensibility indicate an increased perception that smoking is harmful to health and bring into question the quality of life of smokers. ${ }^{(10)}$

Regarding sociocognitive variables, smoking is a behavior in which intention is influenced by the social dimension. Intention is a key aspect of the theory of planned behavior (TPB) and is an important predictor of smoking behavior. ${ }^{(11,12)}$ The $\mathrm{TPB}^{(11)}$ developed from the theory of reasoned action, to which the concept of perceived behavioral control was added. The TPB proposes that an individual's intention to engage in a certain behavior is the key determinant of that behavior, because it reflects the individual's level of motivation and readiness to make efforts to engage in the behavior. Therefore, according to the TPB, behavioral intentions are influenced by three aspects: attitudes toward the behavior; subjective norms; and perceived behavioral control. The TPB states that increasingly favorable attitudes and subjective norms regarding a certain behavior translate to a higher intention to engage in that behavior, as does higher perceived behavioral control. ${ }^{(11)}$ The intention to quit smoking is important, moderating smoking cessation interventions and the effect of medical advice. ${ }^{(13)}$ Therefore, according to the TPB, the most important proximal determinant of behavior is the intention that results from the combination of attitudes toward the behavior, subjective norms, and perceived behavioral control. Beliefs are a central element in the TPB and are considered solid cognitive and affective foundations for the construction of attitudes, subjective norms, and perceived behavioral control.

According to the stress-coping model, ${ }^{(14)}$ in the presence of a stressor (as is the case of smoking), smokers evaluate their characteristics and how they can influence their external or internal resources. These resources will enable smokers to organize appropriate coping strategies to obtain a result, such as quitting smoking.

The objective of the present study was to analyze psychological morbidity as a moderator of the relationship between smoking representations and quality of life in smokers and former smokers, as well as to determine which psychological variables discriminate between smokers with and without the intention to quit smoking.

\section{Methods}

Our study sample was a convenience sample of individuals recruited from among those in the Braga region, in northern Portugal. The participants were recruited during medical consultations (in a central hospital and a private company), in which they were informed of the nature and purpose of the study by the physicians. In the university, the professors were contacted and were asked to inform their students about the study. Subsequently, the participants signed up for the study. Data were collected over a one-year period, and all of the data collection instruments were completed at a single time point. Participation was voluntary, volunteers consenting to participate after having received information on the scope and purpose of the study. The inclusion criteria were being over 18 years of age, being a daily smoker, and having been a former smoker for at least three months.

There were no conflicts of interest, and the study was approved by the research ethics committees of the data collection sites. 
With the objective of analyzing the moderating effect of psychological morbidity on the relationship between smoking representations and quality of life in smokers and former smokers, we used the regression model proposed by Baron and Kenny ${ }^{(15)}$ and simple slopes analysis in order to determine the significance of the interaction among $(t)$ variables. (16) In order to determine which psychological variables discriminate between smokers with and without the intention to quit smoking, we used discriminant analysis. ${ }^{(17)}$

We used the following instruments:

- A sociodemographic questionnaire to obtain information to characterize the study sample in terms of group, marital status, gender, level of education, age, age at smoking onset, attempts to quit smoking, type of treatment, and smoking status of the partner.

- The brief illness perception questionnaire, ${ }^{(10,18)}$ an instrument composed of nine items, which are used in order to assess emotional representations (five items), cognitive representations (two items), and the comprehensibility of the disease (one item). The instrument scores the items on a scale of zero to ten (with the exception of item 9). In terms of internal consistency, given that each scale is composed of only one item and that it is a revised version of the original instrument, it is impossible to calculate Cronbach's alpha coefficient based on factor analysis. The original version refers only to test-retest reliability, which is high. In our study sample, the subscales were moderately correlated with one another, as occurred in the original version. Regarding the scales of cognitive representations, emotional representations, and comprehensibility, high scores indicate threatening cognitive and emotional representations and poorer comprehensibility of the disease.

- The Partner Interaction Questionnaire, ${ }^{(19,20)}$ an instrument composed of one positive scale (eight items) and one negative scale (eleven items), which assess the support that smokers received in the last three months when attempting to quit smoking. This adapted version was developed for a sample of smokers and former smokers, who completed the same questionnaire items. A higher score translates to greater (positive or negative) support from partners.
- The Depression, Anxiety, and Stress Scale, ${ }^{(21,22)}$ an instrument composed of 21 items organized into three subscales (i.e., anxiety, depression, and stress), each subscale comprising seven items. A higher score translates to greater psychological morbidity.

- Medical Outcomes Study 36-item Short-form Health Survey, ${ }^{(23,24)}$ an instrument composed of eight dimensions grouped into two general components (i.e., physical quality of life, comprising 21 items, and mental quality of life, comprising 14 items). A higher score translates to a better perceived quality of life. Rather than an overall scale score, two summary scores are obtained, corresponding to physical quality of life and mental quality of life.

- A TPB questionnaire to assess the intention to quit smoking, ${ }^{(25)}$ which was constructed on the basis of the guidelines proposed by Ajzen ${ }^{(26)}$ and Francis et al. ${ }^{(27)}$ The adapted version of the questionnaire is composed of seven subscalesaction and coping planning; behavioral beliefs; attitudes toward the behavior; perceived behavioral control; subjective norms; normative/ control beliefs; and intention. A high score on the questionnaire indicates a higher value on each scale.

\section{Results}

We recruited 224 daily smokers $(52.7 \%$ of whom were males) and 169 former smokers who had quit smoking at least three months prior (68.6\% of whom were males). Of the smokers, $49.1 \%$ were single and $61.6 \%$ had attended the third year of high school. The mean age of the smokers was $28.58 \pm 8.69$ years (range, 18-58 years). Most of the smokers had been smoking for more than three years, and the age at smoking onset was 14-18 years. Of the smokers, 60\% had made at least one attempt to quit smoking, $96 \%$ had never undergone any smoking cessation treatment, and $56.7 \%$ had a partner who did not smoke. Of the former smokers, $72.8 \%$ were married and 39\% had attended high school. The mean age was 43.10 \pm 13.02 years (range, 19-63 years). Most of the former smokers had started smoking at the age of 12-18 years. All former smokers had made at least one attempt to quit smoking, 32\% having sought smoking cessation treatment. 
In the group of smokers, comprehensibility had a positive predictive effect on mental quality of life $(\beta=0.207 ; p \leq 0.001)$. The interactions between psychological morbidity and emotional representations $(\beta=0.129 ; p$ $\leq 0.001$ ), between psychological morbidity and cognitive representations $(\beta=0.281 ; p \leq$ $0.001)$, and between psychological morbidity and comprehensibility ( $\beta=-0.446 ; p \leq 0.050$ ) were significant. Our results showed that psychological morbidity had a moderating effect on the relationship between mental quality of life and emotional representations $(\mathrm{t}=-2.348 ; \mathrm{p}=$ 0.019 ) and on the relationship between mental quality of life and cognitive representations ( $t$ $=-1.875 ; p<0.001$ ), the relationship being negative when psychological morbidity is low. Psychological morbidity also had a moderating effect on the relationship between mental quality of life and comprehensibility $(\mathrm{t}=4.57$; $p \leq 0.001$ ), the relationship being positive when psychological morbidity is high (Figure 1).

In the group of former smokers, comprehensibility had a positive predictive effect on mental quality of life $(\beta=0.207 ; p \leq 0.001)$. The interaction between psychological morbidity and cognitive representations was significant $(\beta=0.333 ; p \leq 0.001)$. Our results showed that psychological morbidity had a moderating effect on the relationship between mental quality of life and cognitive representations $(t=-1.255$; $p=0.001$ ), the relationship being negative when psychological morbidity is low (Figure 2). Psychological morbidity was found to have no moderating effect on the relationship between mental quality of life and emotional representations or on the relationship between mental quality of life and comprehensibility.

In the group of smokers, emotional representations had a negative predictive effect on physical quality of life ( $\beta=-0.263 ; p \leq 0.001)$, and the interaction between psychological morbidity and emotional representations was significant $(\beta=0.215 ; p \leq 0.001)$. Our results showed that psychological morbidity had a moderating effect on the relationship between physical quality of life and emotional representations $(t=-1.956 ; p=0.005)$, the relationship being negative when psychological morbidity is low (Figure 3). Psychological morbidity was found to have no moderating effect on the relationship between physical quality of life and cognitive representations or on the relationship between physical quality of life and comprehensibility.
In the group of former smokers, cognitive representations had a negative predictive effect on physical quality of life $(\beta=-0.128 ; p \leq 0.050)$, and the interaction between psychological morbidity and cognitive representations was significant ( $\beta$
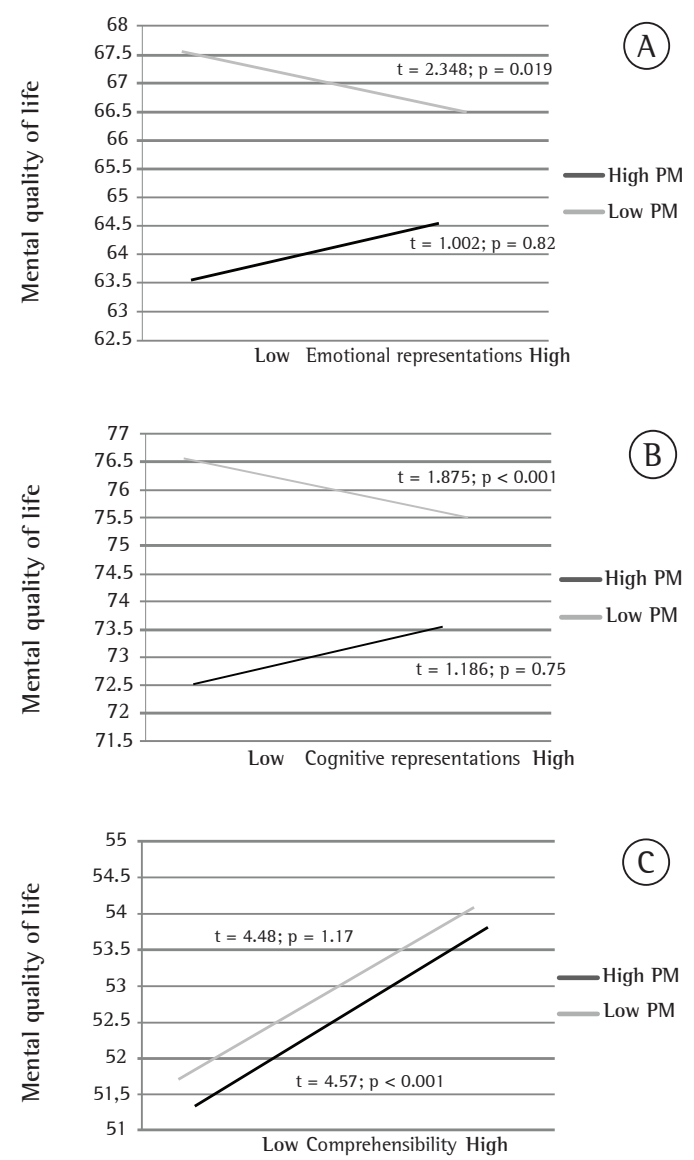

Figure 1 - Moderating effect of psychological morbidity (PM) on the relationship between mental quality of life and and smoking representations in smokers: emotional representations (A), cognitive representations (B), and comprehensibility (C).

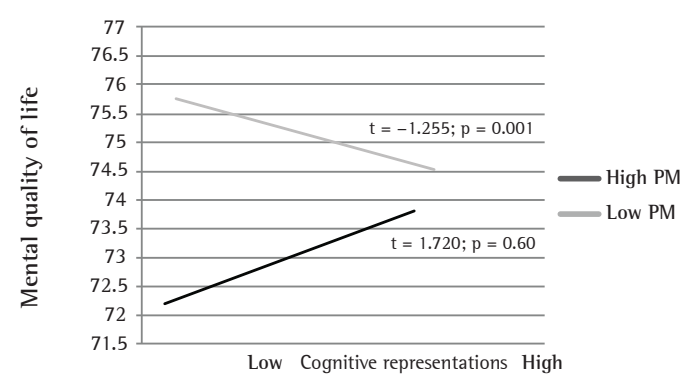

Figure 2 - Moderating effect of psychological morbidity (PM) on the relationship between mental quality of life and cognitive representations in former smokers. 


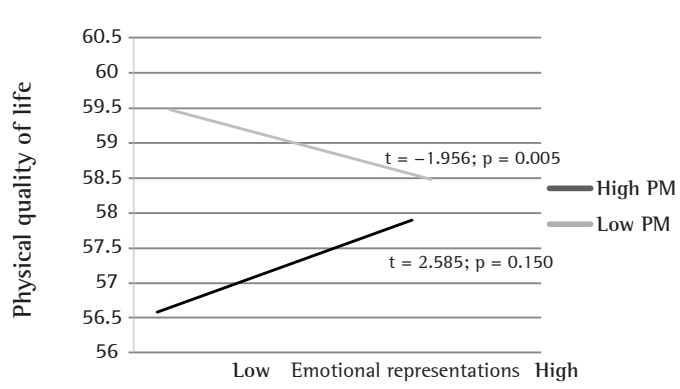

Figure 3 - Moderating effect of psychological morbidity (PM) on the relationship between physical quality of life and emotional representations in smokers.

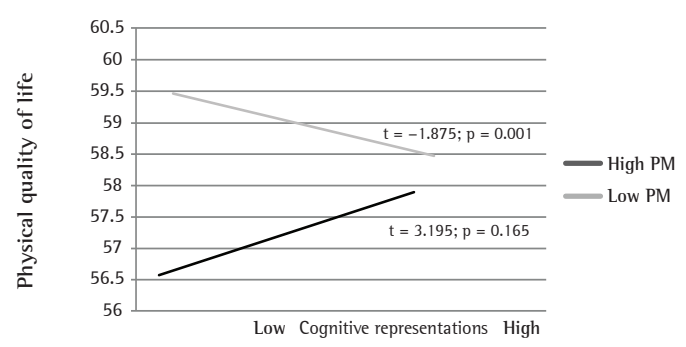

Figure 4 - Moderating effect of psychological morbidity (PM) on the relationship between physical quality of life and cognitive representations in former smokers.

$=0.329 ; p \leq 0.001)$. Psychological morbidity had a moderating effect on the relationship between physical quality of life and cognitive representations $(\mathrm{t}=-1.875 ; \mathrm{p}=0.001)$, the relationship being negative when psychological morbidity is low (Figure 4). Psychological morbidity was found to have no moderating effect on the relationship between physical quality of life and emotional representations or on the relationship between physical quality of life and comprehensibility.

The results of the discriminant analysis showed that $59.8 \%$ of the smokers had the intention to quit smoking, whereas $40.1 \%$ did not. Regarding the variables discriminating between the two groups, the results showed that the smokers who had the intention to quit smoking more often presented with low comprehensibility, threatening emotional representations, behavioral beliefs, and perceived behavioral control, as well as with normative/ control beliefs, than did those who did not.

The relationship between the discriminant function and the original variable, in the case of intention to quit smoking, allowed us to see the contribution of each variable to group discrimination and showed that the most important variable is perceived behavioral control, followed by emotional representations. The discriminant function analysis allowed us to obtain a canonical discriminant variable, with results of significance (Wilk's lambda $=0.495$; chi-square $=$ 71.778; $p \leq 0.001$ ) and a canonical correlation of 0.715 . These results showed that the discriminatory power of the function is significant and that the two groups (smokers with and without the intention to quit smoking) are significantly different on the basis of the study variables.

The results of the functional classification matrix for smokers with and without the intention to quit smoking showed that $77 \%$ of cases are correctly classified, and the proportion of unexplained variance was $49.5 \%$.

\section{Discussion}

The negative relationship between mental quality of life and threatening emotional and cognitive representations of smoking indicates that perceived quality of life decreased as the perceived threat posed by smoking increased. These results can be explained by the literature, which shows that threatening representations are associated with poorer perceived quality of life. ${ }^{(28)}$

By relating this information to the results of our study, we found that threatening (cognitive and emotional) representations of smoking translate to an increased perception that smoking is harmful to health and, consequently, decreased mental quality of life.

The literature shows how psychological morbidity is related to smoking behavior, ${ }^{(3)}$ psychological morbidity having physical consequences at the level of decreased mental quality of life. ${ }^{(2,9)}$ According to the stress-coping model, ${ }^{(13)}$ psychological morbidity can be viewed as an emotional response that can have a direct impact on the outcome measure, i.e., mental quality of life. Also according to the stress-coping model, smoking can be viewed as a stressor that has a direct effect of increasing psychological morbidity and the perceived threat posed by smoking. Therefore, smokers, in the presence of lower psychological morbidity associated with smoking, more often present with low mental quality of life and threatening emotional and cognitive representations; that is, mental quality of life decreases as the perception that smoking is harmful to health increases. Interestingly, the relationship between mental quality of life and comprehensibility is positive. This indicates that, in the presence of higher psychological morbidity, a poorer comprehensibility of the reasons for smoking translates to better mental quality of life as perceived by smokers. Comprehensibility refers 
to smokers knowing why they smoke and what the symptoms related to smoking are. Therefore, psychological morbidity can have a protective effect that will probably maintain smoking behavior in order to protect smokers, giving them the perception of good mental quality of life.

For the former smokers in the present study, psychological morbidity had a moderating effect (which was similar to that observed in the smokers) on the relationship between mental quality of life and cognitive representations. The relationship between quality of life and cognitive representations was negative. This indicates that, in the presence of lower psychological morbidity, the former smokers had shown poorer perceived mental quality of life and threatening cognitive representations when they were smokers. The relationship between physical quality of life and the emotional and cognitive representations of smoking was found to be negative in the smokers and former smokers investigated in the present study; that is, in the presence of fewer symptoms of psychological morbidity in smokers and former smokers, physical quality of life is lower when cognitive and emotional representations of smoking are more threatening. Therefore, threatening cognitive and emotional representations of smoking are associated with lower perceived quality of life, which is in agreement with the literature. ${ }^{(28)}$

The discriminant analysis showed that the smokers who had the intention to quit smoking more often presented with low comprehensibility, threatening emotional representations, behavioral beliefs, and perceived behavioral control, as well as with normative/control beliefs, than did those who did not. According to the literature, ${ }^{(29)}$ smokers who have the intention to quit smoking are in a stage of preparation for quitting smoking. In our study, those who had the intention to quit smoking had a poorer understanding of the reasons for smoking (comprehensibility), showed greater concern with the fact that they smoked, and felt emotionally affected by the threat that smoking posed to their health (emotional representations). These results suggest that smokers in whom the perception that smoking poses a health threat is increased are more motivated to quit smoking. According to the TPB, ${ }^{(30)}$ smokers who have the intention to quit smoking are aware of their control over quitting (perceived behavioral control), take into account what others expect from them (i.e., more often present with normative/control beliefs), and consider the likely outcomes of quitting (i.e., more often present with behavioral beliefs). In fact, the TPB states that beliefs are important in the construction of attitudes, subjective norms, and perceived behavioral control, beliefs being implicated in behavioral intention (to quit smoking).. ${ }^{(30)}$ The sociocognitive variables (perceived behavioral control, behavioral beliefs, and normative/control beliefs) are important in the context of devising a smoking cessation plan. Therefore, threatening emotional representations of smoking and a poorer understanding of smoking lead smokers to believe that smoking is harmful to their health; to show a poorer understanding of the reasons for smoking; and to believe that quitting smoking can be important to their health. ${ }^{(10)}$ The sociocognitive variables in the present study show that perceived behavioral control, normative/control beliefs, and behavioral beliefs play an important role in the intention to quit smoking. ${ }^{(20)}$

The fact that the study sample was a convenience sample of individuals recruited exclusively from among those in northern Portugal limits the generalization of the results to other regions of the country, given that the social and cultural characteristics of each region should be taken into consideration. Future studies should examine the role of sociocognitive variables, particularly in intention, in samples that are more diverse, as well as evaluating the role of family coping as a moderating variable in the relationship between smoking representations and the intention to quit smoking.

The present study underscored the importance of the moderating effect of psychological morbidity on mental and physical quality of life in smokers and former smokers, as well as underscoring the importance of sociocognitive variables in the intention to quit smoking. The results obtained contribute to informing smoking cessation programs regarding a reduction in psychological morbidity and the inclusion of sociocognitive variables (TPB). ${ }^{(12,13)}$

\section{References}

1. Viegas CA. Noncigarette forms of tobacco use. J Bras Pneumol. 2008;34(12):1069-73. http://dx.doi.org/10.1590/ S1806-37132008001200013 PMid:19180343

2. Reichert J, Araújo AJ, Gonçalves CM, Godoy 1, Chatkin JM, Sales MP, et al. Smoking cessation guidelines--2008. J Bras Pneumol. 2008;34(10):845-80. Erratum in: J Bras Pneumol. 2008;34(12):1090. http://dx.doi.org/10.1590/ S1806-37132008001000014 PMid:19009219

3. Aubin HJ, Bobak A, Britton JR, Oncken C, Billing CB Jr, Gong $\mathrm{J}$, et al. Varenicline versus transdermal nicotine 
patch for smoking cessation: results from a randomised open-label trial. Thorax. 2008;63(8):717-24. http:// dx.doi.org/10.1136/thx.2007.090647 PMid:18263663 PMCid:2569194

4. Calheiros $P$, Andretta l, Oliveira M. Avaliação da motivação para mudança nos comportamentos aditivos. In: Werlang BS, Oliveira MS, editors. Temas em Psicologia Clínica. São Paulo: Casa do Psicólogo; 2006.

5. Magid V, Colder CR, Stroud LR, Nichter M, Nichter M; TERN Members. Negative affect, stress, and smoking in college students: unique associations independent of alcohol and marijuana use. Addict Behav. 2009;34(11):973-5. http:// dx.doi.org/10.1016/j.addbeh.2009.05.007 PMid:19523773

6. Miller KE. Quality of life impairment in healthy young smokers. Am Fam Physician. 2004;70(9):1785-6.

7. Sales MP, Oliveira Ml, Mattos IM, Viana CM, Pereira ED. The impact of smoking cessation on patient quality of life. J Bras Pneumol. 2009;35(5):436-41. http://dx.doi. org/10.1590/S1806-37132009000500008 PMid:19547852

8. Trigo M. 0 que provoca realmente a mudança nos fumadores? Algumas reflexões. Rev Port Clin Geral. 2005;21:161-82.

9. Arjonilla S, Pelcastre B Orozco E. Representación social del consumo de tabaco en una institución de salud. Salud Ment. 2000;23(3):2-12.

10. Broadbent E, Petrie KJ, Main J, Weinman J. The brief illness perception questionnaire. J Psychosom Res. 2006;60(6):631-7. http://dx.doi.org/10.1016/j.jpsychores.2005.10.020 PMid:16731240

11. Ajzen 1. From intentions to actions: A theory of planned behavior. ln: Kuhl J, Beckmann J, editors. Action control: From cognition to behavior. Heidelberg: Springer-Verlag; 1985. p. 11-39.

12. Ajzen l, Madden TJ. Prediction of goal-directed behavior: Attitudes, intentions, and perceived behavioral control. J Exp Soc Psychol. 1986;2:453-74. http://dx.doi. org/10.1016/0022-1031(86)90045-4

13. Haug S, Meyer C, Ulbricht S, Schorr G, Rüge J, Rumpf HJ, et al. Predictors and moderators of outcome in different brief interventions for smoking cessation in general medical practice. Patient Educ Couns. 2010;78(1):57-64. http:// dx.doi.org/10.1016/j.pec.2009.07.005 PMid:19660890

14. Maes S, Leventhal H, de Ridder D. Coping with chronic diseases. In: Ziender M, Endler N, editors. Handbook of Coping. New York: Wiley; 1996. p. 221-45.

15. Baron RM, Kenny DA. The moderator-mediator variable distinction in social psychological research: conceptual, strategic and statistical considerations. J Pers Soc Psychol. 1986;51(6):117382. http://dx.doi.org/10.1037/0022-3514.51.6.1173

16. Curran PJ, Bauer DJ, Willoughby MT. Testing main effects and interactions in latent curve analysis. Psychol Methods. 2004;9(2):220-37. http://dx.doi.org/10.1037/1082989X.9.2.220 PMid:15137890

17. Burns RB, Burns RA, editors. Business Research Methods and Statistics using SPSS. London: SAGE Publications Ltd; 2008.
18. Figueiras M, Marcelino DS, Claudino A, Cortes MA, Maroco J, Weinman J. Patients' illness schemata of hypertension: the role of beliefs for the choice of treatment. Psychol Health. 2010;25(4):507-17. http:// dx.doi.org/10.1080/08870440802578961 PMid:20204931

19. Cohen S, Lichtenstein E. Partner behaviors that support quitting smoking. J Consult Clin Psychol. 1990;58(3):304-9. http://dx.doi.org/10.1037/0022-006X.58.3.304

20. Pereira MG, Afonso F. Partner Interaction Questionnaire. Versão de Investigação. Braga: Universidade do Minho; 2006.

21. Lovibond PF, Lovibond SH. The structure of negative emotional states: comparison of the Depression Anxiety Stress Scales (DASS) with the Beck Depression and Anxiety Inventories. Behav Res Ther. 1995;33(3):335-43. http:// dx.doi.org/10.1016/0005-7967(94)00075-U

22. Pais-Ribeiro J, Honrado A, Leal, 1. Contribuição para o estudo da adaptação portuguesa das escalas de ansiedade, depressão e stress de Lovibond e Lovibond. Psic., Saúde \&t Doenças. 2004;5(2):229-39.

23. Ware JE Jr, Sherbourne CD. The MOS 36-item short-form health survey (SF-36). 1. Conceptual framework and item selection. Med Care. 1992;30(6):473-83. http://dx.doi. org/10.1097/00005650-199206000-00002 PMid:1593914

24. Ferreira PL, Santana P. Perceção de estado de saúde e de qualidade de vida da população ativa: Contributos para a definição de normas portuguesas. Rev Port Saúde Publica. 2003;21(2):15-30.

25. Pereira MG, Afonso F. Questionário Sociocognitivo. Versão de Investigação. Braga: Universidade do Minho; 2010.

26. APCC [homepage on the Internet]. Lisboa: APCC [cited 2007 Dec 20]. Ajzen 1. Constructing a TpB Questionnaire: conceptual and Methodological Considerations; 2002. [Adobe Acrobat document, 14p.] Available from: http:// www.apcc.online.pt/upload/membro.id/ficheiros/i005562. pdf

27. lcek Ajzen [homepage on the Internet]. Amherst: University of Massachusetts [cited 2007 Nov 20]. Francis JJ, Eccles MP, Johnston M, Walker A, Grinshaw J, Foy R, et al. Constructing questionnaires based on the theory of planned behavior: A manual for health services researchers; 2004. Available from: http://people.umass.edu/aizen/tpb.html

28. Sampaio RS, Pereira MG, Winck JC. Adaptation of the sleep apnea quality of life index (SAQLI) to Portuguese obstructive sleep apnea syndrome patients [Article in Portuguese]. Rev Port Pneumol. 2012;18(4):166-74. http:// dx.doi.org/10.1016/j.rppneu.2012.02.009 PMid:22541672

29. Prochaska JO, DiClemente CC. Transtheorical therapy: towards a more integrative model of change. Psychol Psychother Theor Res Pract. 1982;19(3):276-88.

30. Ajzen 1. The theory of planned behavior. Organ Behav Hum Dec. 1991;50:179-211. http://dx.doi. org/10.1016/0749-5978(91)90020-T 


\section{About the authors}

Maria Fernanda Besteiro Afonso

Researcher. University of Minho School of Psychology, Braga, Portugal.

Maria Graça Pereira Alves

Associate Professor. University of Minho School of Psychology, Braga, Portugal. 